\title{
ESTRUTURAS PRODUTIVAS NA UNIDADE DE PLANEJAMENTO E GERENCIAMENTO IVINHEMA (MATO GROSSO DO SUL)
}

\author{
Giovane Silveira da SILVEIRA ${ }^{1}$ \\ Lisandra Pereira LAMOSO²
}

\section{Resumo}

As medidas locacionais possibilitam a identificação de padrões de concentração ou dispersão espacial do emprego setorial em um dado período, permitindo qualificar as transformações no emprego de mão de obra formal na região elencada, oferecendo instrumento para políticas públicas e compreensão das estruturas produtivas regionais. Este texto aplica medidas locacionais para o reconhecimento das estruturas produtivas na Unidade de Planejamento e Gerenciamento Ivinhema, no Estado de Mato Grosso do Sul. A pesquisa apontou as vantagens comparativas na produção de commodities e como a utilização dos recursos naturais tem se combinado com políticas públicas de investimento e gerado uma densificação técnica do território, com expansão das estruturas produtivas e inserção no mercado internacional.

Palavras-chave: Estruturas produtivas. Commodity. Recursos naturais. Vantagens comparatias. Emprego

\section{Abstract \\ Productive structures in the unit of planning and management Ivinhema (Mato Grosso do Sul)}

The locational measures allow the identification of concentration patterns or spatial dispersion of sectoral employment in a given period, allowing qualify the transformations in the formal employment in region indicated, offering instrument for public policies and understanding of regional productive structures. This text applies locational measures for the recognition of productive structures in the unit of planning and management Ivinhema in the State of Mato Grosso do Sul. The research pointed out comparative advantages in the production of commodities and as the use of natural resources has combined with public investment policies and generated a technical densification of the territory, with expansion of productive structures and insertion in international market.

Key words: Productive Structures. Commodity. Natural Resources. Comparative Advantages. Employment.

\footnotetext{
1 Doutorando em Geografia pela Faculdade de Ciências Humanas - UFDG. Docente na Universidade Estadual de Mato Grosso do Sul - UEMS. Pesquisador do GEFTA - Grupo de Estudos sobre Fronteira, Território e Ambiente - UNIOESTE. Rua: Itibiré Vieira, s/n; Bairro: Residencial Júlia de Oliveira Cardinal; CEP: 79907-414; Cidade: Ponta Porã: Estado: Mato Grosso do Sul; País: Brasil. E-mail: giovane@uems.br

2 Pós Doutora em Geografia pela Universidade Federal do Rio de Janeiro - UFRJ. Docente na Universidade Federal da Grande Dourados - UFGD. Rodovia Dourados - Itahum, km 12; Cidade Universitária; Caixa Postal: 364. CEP: 79804 - 970; Cidade: Dourados; Estado: Mato Grosso do Sul; País: Brasil. E-mail: lisandralamoso@ufgd.edu.br
} 


\section{INTRODUÇÃO}

O desenvolvimento de técnicas cada vez mais modernas para mapeamento e sistematização de dados tem crescido a tal ponto de nos parecer dotadas de uma autosuficiência explicativa, baseada em retratos datados que clamam por um olhar mais holístico. "Fazer um mapa" tornou-se uma atividade que requer habilidades e conhecimentos específicos, domínio de softwares e linguagens matemáticas, que os programas mais modernos tem buscado simplificar.

O conjunto de instrumentos de representação tem regras bastante rígidas, exigem fidelidade aos procedimentos e apresentam, como resultado, um retrato definido a partir de critérios seletivos. Esses resultados clamam por uma interpretação e são, concomitantemente, o ponto de partida de estudos que, quando contam com representações fiéis, podem agregar valor à compreensão de diversos fenômenos.

Este texto faz um exercício de associar modelos de representação com a interpretação sobre o processo de ocupação do território na Bacia do Rio Ivinhema, mais especificamente na Unidade de Planejamento e Gerenciamento (UPG) Ivinhema, no Estado de Mato Grosso do Sul. O trabalho de representação e sistematização de dados foi realizado com aplicação de medidas locacionais, calibradas por meio de dados sobre o emprego formal obtidas na Relação Anual de Informações Sociais (RAIS) disponibilizadas pelo Ministério do Trabalho e Emprego (MTE).

O que as medidas locacionais podem nos apresentar? Para Lima e Simões (2010, p. 44) em termos de medidas locacionais tem-se que "seu objetivo é identificar padrões de concentração ou dispersão espacial do emprego setorial em um dado período." Essa informação nos permite quantificar e qualificar as transformações no emprego de mão de obra formal na região elencada, o que em termos de políticas públicas pode ser muito útil para situações de implementação de programas de qualificação de mão de obra e mesmo crédito agrícola.

Delimitamos a pesquisa pelas atividades agropecuárias: criação de bovino, suíno e aves como também o cultivo de soja, cana de açúcar e cereais, a isso somando-se os serviços relacionados à agricultura e pecuária. Esses produtos foram selecionados a partir da revisão bibliográfica, que apontou serem os mais representativos em volume e área ocupada.

A justifica para a escolha de atividades econômicas agropecuárias está no fato de que "os recursos naturais são essenciais à sobrevivência da humanidade e que devemos compreender os processos que atuam em suas formações" (ZANATA, 2014, p. 13), entendendo-se para o presente trabalho tais "formações" como "transformações" ocasionadas por meio de atividades econômicas de uso e ocupação direta sobre a terra, as quais atuam de forma visível sobre sua superfície e transformam radicalmente a paisagem já antrópica segundo interesses econômicos. Haja vista que a paisagem de uma bacia hidrográfica pode ser constituída por elementos como, por exemplo: "água, relevo, solo, flora, fauna, pastagem, agricultura, residências, indústrias, população, economia, etc." (DIBIESO, 2013, p. 21). Por conseguinte, a compreensão das atividades econômicas que se desenvolvem no entorno de uma bacia hidrográfica constitui-se em elemento de relevância para o planejamento ambiental, haja vista que "a gestão territorial pressupõe uma interação das ações espaciais no que concerne ao uso e ocupação do espaço, considerando os atributos naturais, sociais e econômicos" (OLIVEIRA, 2003, p. 17).

$\mathrm{Na}$ primeira seção, descrevemos detalhadamente os procedimentos seguidos para a elaboração do resultado cartográfico e como se constrói as medidas locacionais, como forma de compartilhar o processo de construção dos resultados. O propósito é que tal metodologia possa ser replicada para estudos de outras diferentes áreas, por 
isso, nos detivemos na explicação detalhada de como os dados foram coletados e tratados. Na segunda seção, procuramos compreender o que apresentam os dados, utilizando informações da revisão bibliográfica e alguns levantamentos de trabalho de campo.

\section{A SISTEMATIZAÇÃO DA BASE DE DADOS}

Na primeira parte do trabalho expomos como se dá o fluxo hidrológico dos rios que compõe a UPG do Ivinhema, como o Rio Brilhante, Dourados, Vacaria e Ivinhema. $\mathrm{Na}$ segunda parte é apresentada a metodologia das medidas locacionais e, na sequência, são apresentados os resultados na forma de tabela e ilustrados por mapas coropléticos.

Com o intuito de entender o fluxo hidrológico criou-se um retângulo envolvente para o conjunto de municípios do UPG Ivinhema, que posteriormente foi carregado no sítio da internet referente ao Serviço Geológico dos Estados Unidos, United State Geological Survey, (USGS). A fim de cobrir o retângulo envolvente dos municípios que compõe a UPG do Ivinhema foi necessário realizar o download de 20 imagens de satélite do tipo fornecido pela Missão Topográfica Radar Shuttle (SRTM). As imagens foram unidas na forma de mosaico no QGIS e, posteriormente alteradas suas coordenadas para o tipo de Albers. As imagens SRTM fornecidas pelo USGS estão originalmente em coordenadas geográficas do tipo WGS 84. Com o intuito de realizar as operações como de relevo, por exemplo, é necessário converter tais imagens para coordenadas planas, ou projetadas. O modo comum de proceder em tal situação é convertê-las em Universal Transversa de Mercator (UTM). Todavia, o mosaico SRTM tem metade de sua porção no fuso 21 e a outra metade no fuso 22, o que impossibilita o uso do formato UTM. Por conseguinte adotou-se a Projeção Cônica de Albers. Onde as imagens SRTM adotadas foram do tipo 1 arco por segundo com pixel de 30 metros.

Além do mosaico SRTM também processou-se a criação de um arquivo do tipo shapefile com o perímetro dos municípios que compõe a UPG Ivinhema. Tal arquivo também foi convertido para a projeção Albers com o intuito de que o mesmo fosse utilizado para efetuar um recorte no mosaico SRTM e, assim, delimitar de forma mais acentuada a região de estudo. Na sequência classificou-se a altimetria com cores quentes para as áreas altas e cores frias para as áreas de baixa altitude. A relevância de um mapa altimétrico para o presente estudo consiste no fato de que por meio de tal representação cartográfica torna-se possível conhecer a direção do fluxo hidrológico. De acordo com o Instituto Brasileiro de Geografia e Estatística (IBGE), (BRASIL, 1998, p. 82),

cursos estendem-se do ponto mais alto (nascente ou montante) até o ponto mais baixo (foz ou jusante), que pode corresponder ao nível [...] de outro rio do qual é afluente. Outros elementos que colaboram no entendimento da direção do fluxo hídrico são os fisiográficos naturais como as serras, com destaque para esta região à de Maracajú. Para a bacia do Ivinhema tem-se a Serra de Maracajú à noroeste e o rio Paraná à sudeste. Por conseguinte pode-se auferir que a direção do fluxo hídrico na bacia do Ivinhema dá-se no sentido noroeste para sudeste. Ao considerar a serra como "cadeia de montanhas. Muitas vezes possui um nome geral para todo o conjunto e nomes locais para alguns trechos. 
Na bacia, temos uma altitude de, aproximadamente, 736 metros no ponto mais alto, nas proximidades da Serra de Maracajú, e o conjunto de terras drenadas pelo Ivinhema e seus afluentes e deste até o Rio Paraná apresenta uma altimetria de 195 metros (ver figura 1). Os rios principais são Dourados, Brilhante e Vacaria, sendo que os dois últimos formam o rio Ivinhema.

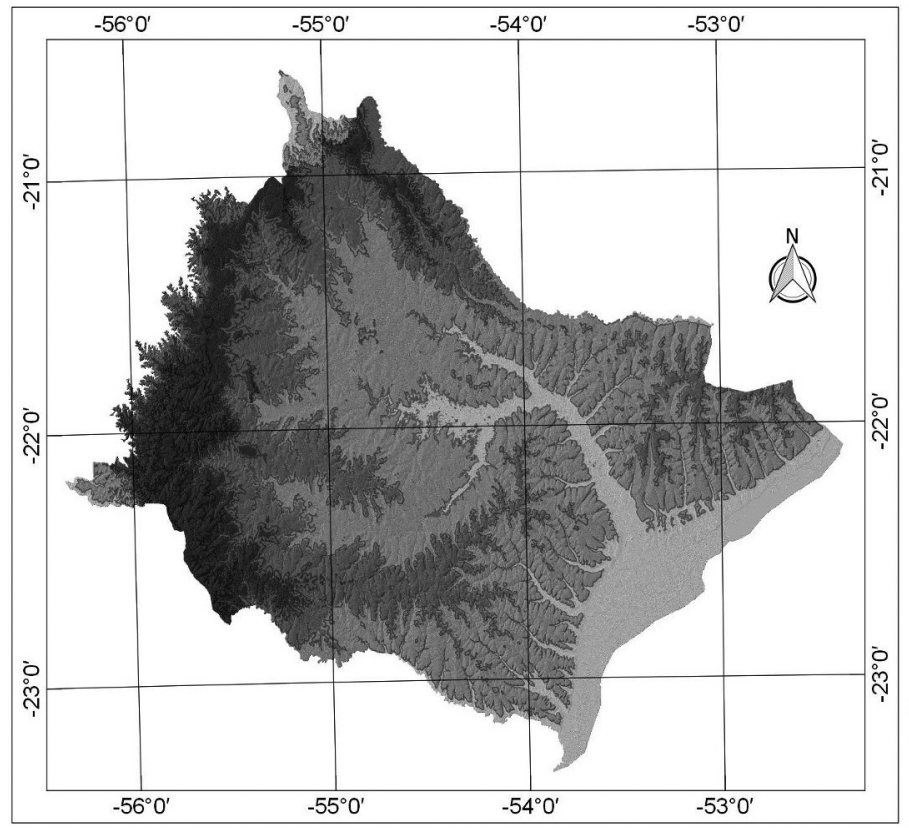

Altimetria

(em metros)

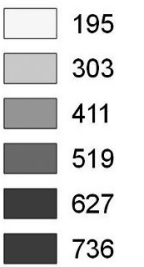

Escala

$1: 3.600 .000$

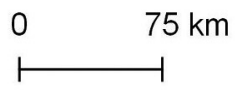

Projeção: Albers Datum: SIRGAS 2000

Cartografia: Giovane Silveira Software: QGIS 2.14 Essen Malha Digital: IBGE e ANA Fonte: SRTM e USGS

Figura 1 - Mapa altimétrico da UPG Ivinhema

Em termos de método o presente estudo contempla as medidas locacionais, sendo adotadas três destas medidas no presente trabalho: Coeficiente de Localização, Coeficiente de Associação Geográfica e Coeficiente de Redistribuição. A metodologia de análise de dados do presente trabalho pode ser sintetizada por meio da tabela 1: 
Tabela 1 - Medidas Locacionais

\begin{tabular}{|c|c|c|}
\hline $\begin{array}{l}\text { Coeficiente de } \\
\text { Localização do } \\
\text { setor } \mathbf{i}\left(\mathrm{CL}_{\mathrm{i}}\right)\end{array}$ & $\begin{array}{l}\text { Equação: } \\
\qquad \mathrm{CL}_{\mathrm{i}}=\frac{\sum_{\mathrm{j}}\left(\left|\mathrm{j}^{\mathrm{ei}}-\mathrm{j}^{\mathrm{eo}}\right|\right)}{2}\end{array}$ & $\begin{array}{l}\text { Definição: } \\
\text { Examina a distribuição espacial da atividade } \\
\text { econômica do setor } \mathrm{i} \text { em relação a região de } \\
\text { referência. }\end{array}$ \\
\hline $\begin{array}{l}\text { Condição: } \\
0 \leq \mathrm{CL}_{i} \leq 1\end{array}$ & \multicolumn{2}{|c|}{$\begin{array}{l}\text { Valores próximos de } 0 \text { indicam semelhança na distribuição espacial da estrutura } \\
\text { produtiva; Todavia, valores próximos de } 1 \text { apontam para concentração na } \\
\text { estrutura produtiva. }\end{array}$} \\
\hline $\begin{array}{l}\text { Coeficiente de } \\
\text { Associação } \\
\text { Geográfica entre os } \\
\text { setores i e } k\left(C_{i k}\right)\end{array}$ & $\begin{array}{l}\text { Equação: } \\
\qquad \mathrm{CA}_{\mathrm{ik}}=\frac{\sum_{\mathrm{j}}\left(\left|\mathrm{j}^{\mathrm{ei}}-\mathrm{j}^{\mathrm{ek}}\right|\right)}{2}\end{array}$ & $\begin{array}{l}\text { Definição: } \\
\text { Identifica a distribuição espacial do setor i em } \\
\text { relação ao setor k. }\end{array}$ \\
\hline $\begin{array}{l}\text { Condição: } \\
0 \leq \mathrm{CA}_{\mathrm{ik}} \leq 1\end{array}$ & \multicolumn{2}{|c|}{$\begin{array}{l}\text { Se estiver próximo a } 0 \text { indica que os setores apresentam distribuição espacial } \\
\text { semelhantes. Caso esteja próximo de } 1 \text { então indicam para o fato de os setores } \\
\text { não estarem geograficamente associados. }\end{array}$} \\
\hline $\begin{array}{l}\text { Coeficiente de } \\
\text { Redistribuição do } \\
\text { setor i entre os } \\
\text { períodos inicial e } \\
\text { final }\left(C_{R_{i}}\right)\end{array}$ & $\begin{array}{l}\text { Equação: } \\
\qquad \mathrm{CR}_{\mathrm{i}}=\frac{\sum_{\mathrm{j}}\left(\left|\mathrm{j}_{\mathrm{t} 1}^{\mathrm{ei}}-\mathrm{j}_{\mathrm{t} 0}^{\mathrm{ei}}\right|\right)}{2}\end{array}$ & $\begin{array}{l}\text { Definição: } \\
\text { Avalia a alteração na distribuição espacial do } \\
\text { setor i entre os períodos inicial }\left(t_{0}\right) \text { e final }\left(t_{1}\right) \text {. }\end{array}$ \\
\hline $\begin{array}{l}\text { Condição: } \\
0 \leq \mathrm{CR}_{\mathrm{i}} \leq 1\end{array}$ & \multicolumn{2}{|c|}{$\begin{array}{l}\text { Próximos de } 0 \text { indicam que o setor tornou-se concentrado; } \\
\text { Já valores próximos de } 1 \text { apontam que o setor tornou-se disperso. }\end{array}$} \\
\hline \multicolumn{3}{|c|}{ Em que: } \\
\hline Variável: & \multicolumn{2}{|r|}{ Definição: } \\
\hline$E_{i j}$ & \multicolumn{2}{|c|}{ Refere-se ao emprego do setor i na região $j$. } \\
\hline$E_{o j}=\sum_{i} E_{i j}$ & \multicolumn{2}{|c|}{ Total de empregos de todos setores para a região $\mathrm{j}$. } \\
\hline$E_{i o}=\sum_{j} E_{i j}$ & \multicolumn{2}{|c|}{ Total de empregos de todas as regiões para o setor $\mathrm{i}$. } \\
\hline$E_{0 o}=\sum_{j} \sum_{i} E_{i j}$ & \multicolumn{2}{|c|}{ Total de empregos de todos os setores i e regiões $j$. } \\
\hline Variável: & Condição: & Sendo que: \\
\hline$i_{j}^{e}=\frac{E_{i j}}{\sum_{i} E_{i j}}$ & $\sum_{i} i_{j}^{e}=1$ & $i_{o}^{e}=\sum_{j} i_{j}^{e}$ \\
\hline$j_{i}^{e}=\frac{E_{i j}}{\sum_{j} E_{i j}}$ & $\sum j_{j}^{e}=1$ & $j_{o}^{e}=\sum_{i} j_{i}^{e}$ \\
\hline
\end{tabular}

Fonte: adaptado pelos autores a partir de Lima e Simões (2010).

Já as unidades administrativas que compõem a bacia do rio Ivinhema, ou mais precisamente a UPG Ivinhema, tanto de forma parcial como completa, podem ser verificadas na figura 2. O Estado de Mato Grosso do Sul conta com um total de 79 municípios distribuídos em 19 UPG de recursos hídricos, dos quais 25 municípios fazem parte da UPG do Ivinhema. Em termos de geoprocessamento o presente trabaIho adotou para uso o programa QGIS 2.14 Essen. Por meio do documento Plano de Gestão dos Recursos Hídricos de Mato Grosso do Sul (IMASUL, 2010) anotou-se o nome dos municípios que compõe a UPG do Ivinhema, sendo possível destacar tais municípios na malha digital do IBGE referente aos municípios de Mato Grosso do Sul. 


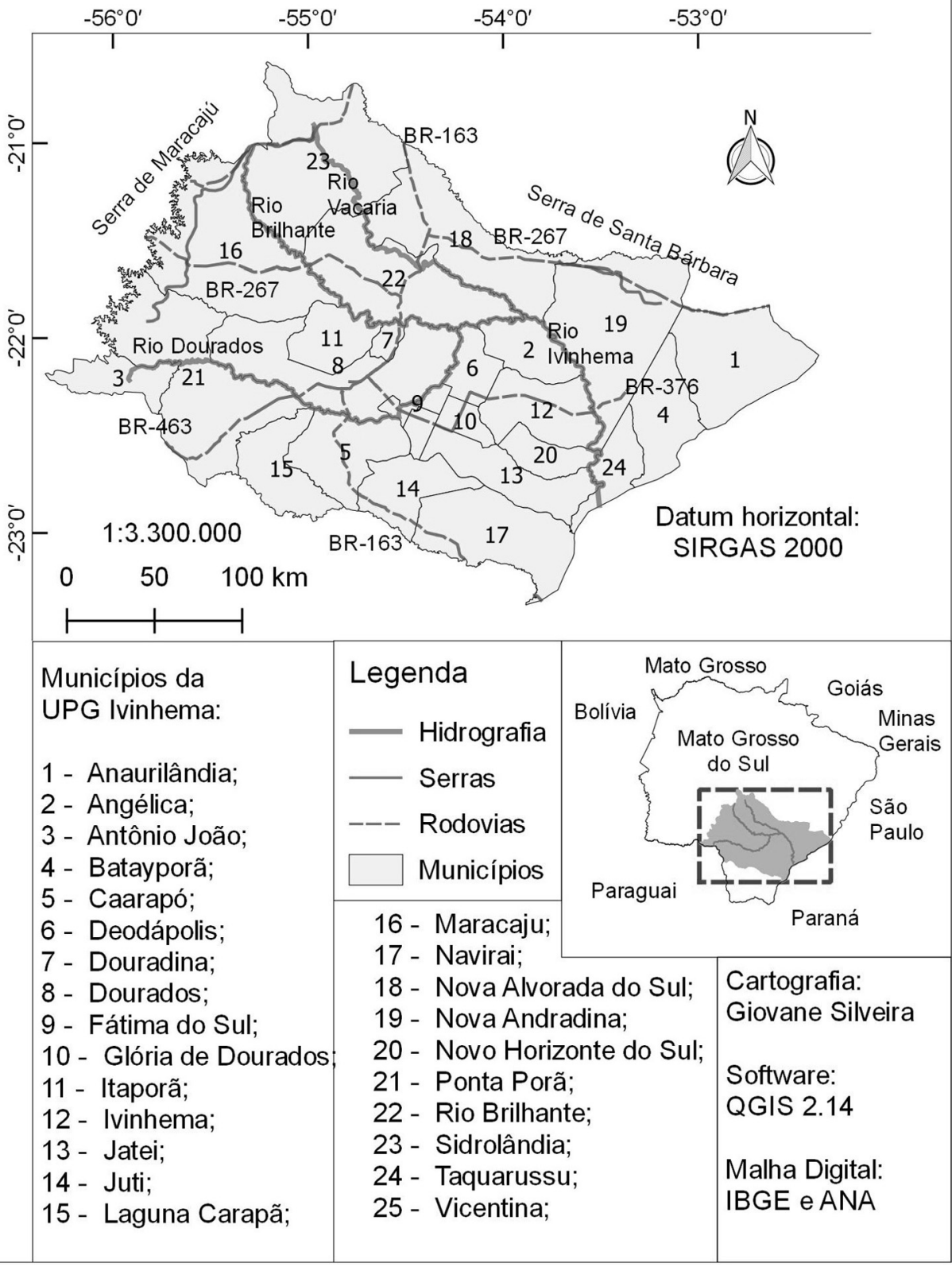

Figura 2 - Municípios que fazem parte da Unidade de Planejamento e Gerenciamento Ivinhema (MS) 
Para cada um dos referidos municípios que compõe a UPG Ivinhema foram coletados e tabulados dados referentes ao número de empregos formais para os setores selecionados de cultivo, criação e serviços. Assim, para cultivo foram selecionados o de cana de açúcar, soja e cereais. Já para criação teve-se as de bovino, suíno e aves. $E$, para os serviços, aqueles relacionados a agricultura e pecuária.

Tais dados foram obtidos junto ao Ministério do Emprego e Trabalho (MTE) por meio da Relação Anual de Informações Sociais (RAIS) que "em razão de sua multiplicidade de informações de interesse social, possui um enorme potencial como fonte de dados, capaz de subsidiar os diagnósticos e fundamentar as políticas públicas" (MTE, 2013, p. 1) a qual constitui-se em uma das "principais fontes de informações sobre o mercado de trabalho, sendo utilizada pelo governo na elaboração de políticas públicas e também para a tomada de decisões dos mais diversos segmentos sociais (empresas, acadêmicos, sindicatos, etc.)" (MTE, 2014, p. 1). Por conseguinte, como ressaltam Betarelli Junior e Simões (2011, p. 8) a "principal vantagem da RAIS é o nível detalhado de desagregação geográfica e setorial dos dados".

A RAIS "como toda fonte de informação, apresenta vantagens e limitações quanto ao uso de seus dados" (MTE, 2013, p. 1), assim tal base de dados deve ser utilizada com algumas precauções, em virtude de que os estabelecimentos que alimentam o cadastro podem fornecer informações fora do prazo, incompletas e incorretas, além de omissões. Soma-se à isso o fato de que alguns setores são mais afetados pelos fatores mencionados anteriormente, dentre eles destaca-se a Agricultura. E, apesar das informações fornecidas divergirem de outras pesquisas e estudos realizados para manutenção de banco de dados, deve-se ressaltar que, "consideradas suas particularidades, em termos gerais, verifica-se igual tendência na evolução do fenômeno" (MTE, 2014, p. 3). Outra observação, como destacam Betarelli Junior e Simões (2011, p. 8) está no fato de que "sua limitação, contudo, reside principalmente na exclusiva cobertura de emprego formal e dos estabelecimentos com mais de cinco empregados registrados".

Acreditamos que as bases de dados disponíveis, como no caso da RAIS, são pouco conhecidas e por isso, pouco exploradas pelos pesquisadores tanto das Ciências Humanas quanto das Ciências Sociais Aplicadas, dadas suas fragilidades. Até mesmo por isso, é necessário investirmos na exploração desses bancos de dados para que as demandas científicas funcionem como um estímulo ao seu aperfeiçoamento. É com esse ponto de partida que nos dedicamos a valorizar a base de dados da RAIS como importante fonte para o reconhecimento de fenômenos geográficos e como instrumento de gestão e ordenamento territorial.

Sobre o recorte temporal do presente trabalho tem-se que as pesquisas que contemplam medidas locacionais estabelecem um intervalo que na média compreende um período superior a 10 anos. Em consulta ao sítio da internet do Ministério do Emprego e Trabalho para obtenção de dados sobre Emprego Formal na Relação Anual de Informações Sociais em agosto de 2015, constatou-se que o último ano contemplado para os quais os dados estão disponíveis é 2014. O que leva à um recuo temporal até 2004. Como algumas medidas prescindem de dois períodos, então seria razoável um segundo período de 2004 a 1994. Todavia, devido à indisponibilidade de dados para alguns municípios no ano de 1994, utilizou-se então o ano de 1995, o que não compromete a análise. A qual poderia ser perturbada se a escolha recaísse para um ano com ausência de dados, como o de 1994.

No presente estudo foram utilizados setores da Classificação Nacional de Atividade Econômica de 1995, os quais são: Cultivo de cereais para grãos (Cód. 1112), Cultivo de cana-de-açúcar (Cód. 1139), Cultivo de soja (Cód. 1155), Criação de bovinos (Cód. 1414), Criação de suínos (Cód. 1449), Criação de aves (Cód. 1457), Atividades de serviços relacionados com a agricultura (Cód. 1619) e Atividades de 
serviços relacionados com pecuária (Cód. 1627). Evidente que estão disponíveis outros setores relacionados tanto à cultivo, quanto à criação e também atividades relacionadas à prestação de serviços. Todavia, as mencionadas neste parágrafo foram consideradas como mais representativas do setor agropecuário em virtude da magnitude do volume de emprego alocado em relação às atividades econômicas omitidas.

\section{A ESTRUTURA DO EMPREGO FORMAL NO SETOR AGROPECUÁRIO}

Passemos, agora, para a abordagem das medidas locacionais, dentre elas, a primeira, coeficiente de localização, tem como objetivo identificar o grau de dispersão da atividade econômica na região de referência, neste caso os municípios que fazem parte da UPG Ivinhema. O grau de concentração, ou dispersão, é dado em relação ao tipo de atividade econômica realizada em tal região. Seu valor varia entre zero e um. Quanto mais próximo de um, então maior o nível de concentração da atividade. Ou seja, o número de empregos formais para a atividade estará reduzido para um conjunto restrito de municípios. Por conseguinte, quanto mais próximo de zero, maior o nível de dispersão atividade na região da bacia. Em outras palavras, haverá uma constatação da presença de empregos formais da atividade econômica para um amplo número de municípios que pertencem à UPG.

Por meio da tabela 2, pode-se perceber que a atividade econômica que apresenta um maior nível de dispersão na região, para os anos delimitados é a de criação de bovinos. Haja vista que sendo seu valor $(0,21)$ está mais próximo de zero em relação aos valores obtidos para cana-de-açúcar $(0,82)$, suínos $(0,73)$ e aves $(0,65)$ que sendo maiores que 0,5 estão próximos de $1 \mathrm{e}$, portanto, indicam para uma concentração destas atividades produtivas. Ou seja, apontam para o pertencimento destas atividades em um número restrito de municípios. A pecuária possui uma espacialização mais generalizada, fruto do processo de ocupação do próprio território brasileiro e, no caso de Mato Grosso do Sul, das vias de entrada do processo de ocupação, pelo norte, com os pecuaristas mineiros, pelo leste, com pecuaristas vindos de São Paulo, como demonstra Bertholi (2006). Esta espacialização se manteve em todos os anos pesquisados, sendo a maior entre as atividades pesquisadas.

Tabela 2 - Coeficiente de Localização para a Bacia do Ivinhema

\begin{tabular}{ccccccccc}
\hline & \multicolumn{2}{c}{ Cultivo } & \multicolumn{2}{c}{ Criação } & \multicolumn{2}{c}{ Serviços } \\
\hline Ano & Cereais & Cana & Soja & Bovinos & Suínos & Aves & Agricultura & Pecuária \\
\hline 2014 & 0,43 & 0,59 & 0,37 & 0,27 & 0,65 & 0,63 & 0,36 & 0,46 \\
\hline 2004 & 0,51 & 0,48 & 0,41 & 0,19 & 0,55 & 0,60 & 0,41 & 0,43 \\
\hline 1995 & 0,51 & 0,82 & 0,58 & 0,21 & 0,73 & 0,65 & 0,49 & 0,47 \\
\hline
\end{tabular}

Fonte: elaborado pelos autores a partir dos dados de RAIS-CAGED-MTE.

Por meio da figura 3 pode-se observar que o município de Nova Andradina e Anaurilândia, em 2014, são aqueles que concentram o maior número de empregos para a atividade de criação de bovinos. De acordo com Oliveira, Urchei e Fietz (2000, p. 15) na região em torno da cidade de Nova Andradina "o relevo é esculpido sobre litologias areníticas cretácicas do Grupo Bauru, que originaram Latossolos Vermelho- 
Escuros álicos, sobre os quais se desenvolvia originalmente vegetação de Savana (Cerrado)" o que pode colaborar para a intensificação de tal atividade de criação nesta localidade. Historicamente, Nova Andradina foi município selecionado para a instalação de frigorífico de abate de gado bovino e abriga, em 2016, planta industrial da unidade do Marfrig, Galera (2011).

As condições naturais funcionam como um recurso original e atrativo para a atividade, que pode permanecer com o passar do tempo, de acordo com os interesses que as classes sociais hegemônicas impõe ao território e, com isso, a densificação técnica que serve à atividade vai se materializando, como a presença do frigorífico, das empresas de transporte, da qualificação da força de trabalho, das linhas de crédito para implantação das unidades industriais, políticas de estímulo e renúncia fiscal e outras mais. Em Nova Andradina, agrega-se um sítio próximo ao Estado de São Paulo, cujos proprietários de terra ou arrendatários ligados à pecuária extensiva, migram em busca de terras mais baratas ou valores de arrendamento com preços mais baixos que o estado de São Paulo.
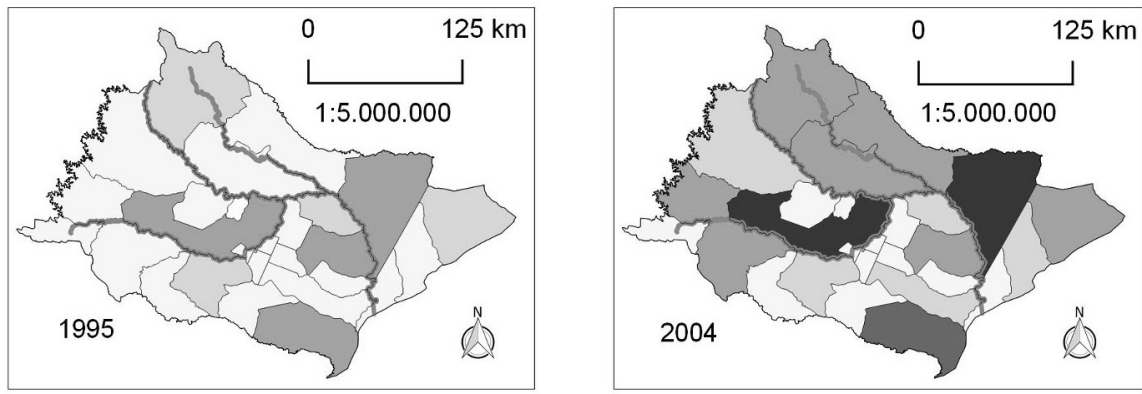

$$
\begin{aligned}
& \text { Empregos formais } \\
& \text { na criação de bovinos } \\
& 10-200 \\
& 200-400 \\
& 400-600 \\
& 600-800 \\
& 800-1000
\end{aligned}
$$

Cartografia: Giovane Silveira da Silveira
Software de Cartomática: QGI 2.14 Essen
Malha Digital: IBGE e ANA
Fonte de dados: RAIS/CAGED

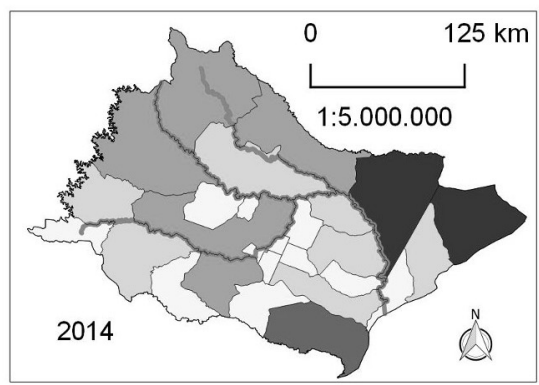

Figura 3 - Quantidade de Emprego Formal na criação de bovinos para a UPG Ivinhema nos anos de 1995, 2004 e 2014

Vale ressaltar, ainda sobre os resultados obtidos por meio da primeira medida locacional que o número de empregos formais na atividade pecuária tem aumentado de 1995 a 2014. Isto se deve às imposições da legislação trabalhista mais que ao maior emprego efetivo em si. Antes, predominava uma informalidade na relação de trabalho, sem o necessário registro na carteira e oficialização junto à previdência social. Com a expansão das oportunidades de emprego fora da área rural e à inten- 
sificação do processo de urbanização, foi se tornando mais difícil, para os proprietários pecuaristas, encontrar mão de obra para residir nas fazendas e lidar com a criação. Isso foi demandando a oficialização das relações de trabalho, que é apresentada nas estatísticas de emprego. Predominam nessas relações, a moradia do casal, na fazenda, os filhos em idade escolar já se acomodando nas cidades e um meio de transporte que os coloque em contato mais frequente com a materialidade do cotidiano urbano.

Já a segunda medida locacional a ser abordada neste trabalho, o coeficiente de associação geográfica, revela o padrão de alocação do emprego de um determinado setor para com outro relacionado. Assim, conforme Lima e Simões (2010, p. 10), "ele permite identificar se a distribuição espacial do emprego em determinado setor é semelhante à distribuição espacial do emprego nos demais setores". Assim, informa se a distribuição do emprego no setor i, por exemplo, está semelhante ao do setor k. Quanto mais próximo de zero, maior a associação geográfica, por conseguinte, quanto mais próximo de 1 , menor tal associação.

De todas as combinações com os setores agropecuários destaca-se as que constam na tabela 3 onde é possível enfatizar uma associação geográfica entre os setores de cereais e aves, como também de cereais e soja. Os quais apresentam valores menores do que 0,5 o qual pode ser entendido como valor de corte que divide os próximos de zero (menores que 0,5 ) e próximos de 1 (maiores que 0,5 ). Cereais e Aves apresentam valores de 0,48 o que revela uma associação geográfica na alocação de emprego formal destes setores, pois a concentração da atividade de criação de aves é pertinente e colaborada por meio da concentração da atividade de cultivo de cereais, haja vista que esta última constitui-se como matéria-prima da primeira.

\section{Tabela 3 - Coeficiente de Associação Geográfica para a Bacia do Ivinhema}

\begin{tabular}{ccc}
\hline \multicolumn{2}{c}{ Associação Geográfica entre os setores de: } & $\mathbf{2 0 1 4}$ \\
\hline Cereais & Aves & 0,48 \\
\hline Bovino & Serv. Pecuária & 0,44 \\
\hline Cereais & Soja & 0,24 \\
\hline Fonte: elaborado própria & com dados de RAIS-CAGED-MTE.
\end{tabular}

Frata e Faria (2010) abordam a bacia do Ivinhema em duas partes, aquela entre a foz do Rio Dourados, Brilhante e Vacaria até a Serra de Maracaju, a qual denominam como Alta Sub-Bacia do Ivinhema e a parte da foz dos rios mencionados até a calha do Rio Paraná, como a Baixa Sub-Bacia do Ivinhema. Por meio da figura 4 pode-se observar uma concentração das atividades de soja e cereais na Alta SubBacia do Ivinhema. Por conseguinte "A parte alta está entre as mais importantes regiões produtoras de grãos e a parte baixa tem na produção de gado de corte, inclusive para exportação, sua característica econômica principal." (FRATA; FARIA, 2010, p. 11).

No ano de 2014, o número de empregos formais na atividade da soja encontra sua maior classe (914-1142 empregos) no município de Maracaju, que é o maior produtor de soja do estado. O cinturão no Centro Oeste do Estado é formado por Sidrolândia, Rio Brilhante, Maracaju, Dourados, Ponta Porã, Laguna Caarapã e Caarapó. Itaporã e Douradina, fazem parte embora com menos empregos formais no setor até porque são municípios com uma população economicamente ativa menos expressiva. 


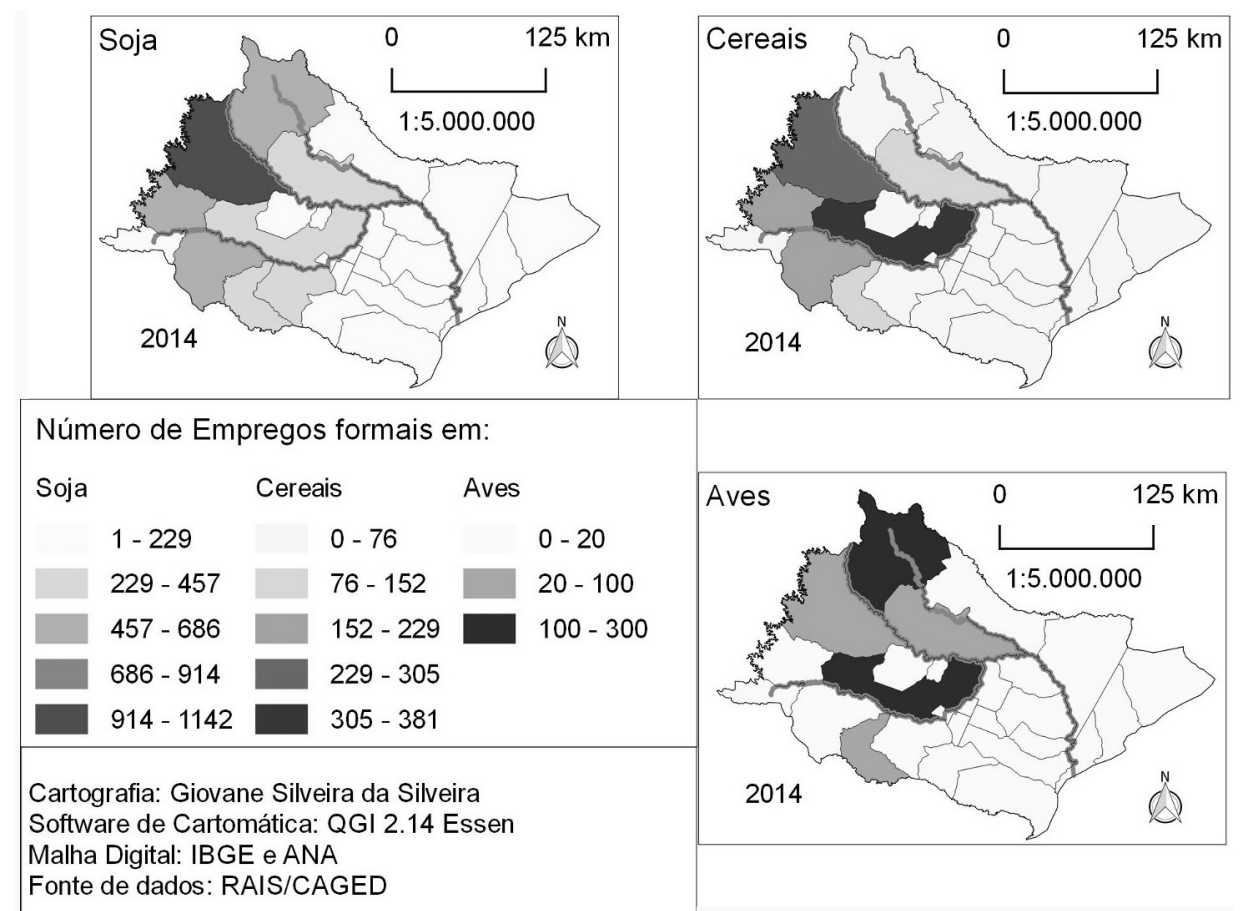

\section{Figura 4 - Quantidade de Emprego Formal na criação de aves e cultivo de soja como também cereais para a UPG Ivinhema em 2014}

Maracaju possui vantagens comparativas tanto naturais quanto produzidas por investimentos, know how e predomínio da cultura dos granjeiros sulistas que adquiriram terras no sul do Estado para a produção de grãos, ver tabela 4. Justamente por deter vantagens comparativas, sua produtividade é a mais elevada do Estado e isso não impediu o município de verticalizar a estrutura produtiva em direção à industrialização, apontando para uma verticalização da cadeia produtiva que utiliza a vantagem na produção de commodities. Estão anunciados investimentos de US\$500 miIhões de dólares pela BBCA Brasil, empresa que pertence ao grupo JLJ Empresas. Trata-se de uma unidade industrial química a partir do processamento do milho e cogeracão de energia por uma empresa estatal chinesa para a produção de ácido cítrico, onde o acordo foi assinado em 19 de maio de 2016 em Brasília, entre o Governo de Mato Grosso do Sul, o grupo BBCAA e o China Development Bank, que participará do financiamento.

A capacidade a ser instalada para processamento de milho será de 1,25 milhão de toneladas/ano e 1 milhão de tonadada/ano de soja. Além da produção de ácido cítrico, estão previstos produção de xarope de maltose, amido de milho, dextrose cristalina, lisina e outros derivados que tem emprego na indústria alimentícia. Os investimentos foram divulgados pela imprensa local e internacional, em manchetes disponíveis em: http://www.noticias.ms.gov.br/reinaldo-assina-acordo-com-grupochines-e-consolida-investimentos-em-mato-grosso-do-sul/ e http://brasil.elpais.com/ brasil/2015/05/19/politica/1432055156_250412.html (acesso em 17 de outubro de 2016). 


\section{Tabela 4 - Município de Maracaju - Área plantada e quantidade produzida de soja, milho e cana-de-açúcar (2006 - 2012)}

\begin{tabular}{ccccccc}
\hline Ano & $\begin{array}{c}\text { Área } \\
\text { Plantada } \\
\text { (ha) }\end{array}$ & $\begin{array}{c}\text { Soja } \\
\text { Produzida } \\
\text { (t) }\end{array}$ & $\begin{array}{c}\text { Qtd. } \\
\text { Plantada } \\
\text { (ha) }\end{array}$ & $\begin{array}{c}\text { Milho } \\
\text { Produzida } \\
\text { (t) }\end{array}$ & $\begin{array}{c}\text { Cana-de-açúcar } \\
\text { Alanta } \\
\text { (ha) }\end{array}$ & $\begin{array}{c}\text { Qtd. } \\
\text { Produzida } \\
\text { (t) }\end{array}$ \\
\hline 2006 & 185000 & 488400 & 67000 & 243600 & 14597 & 1444402 \\
\hline 2007 & 180000 & 561600 & 92000 & 334800 & 20000 & 1980000 \\
\hline 2008 & 180000 & 507600 & 112000 & 441600 & 24227 & 2422700 \\
\hline 2009 & 180000 & 496800 & 117320 & 272352 & 26829 & 2814667 \\
\hline 2010 & 187000 & 583440 & 131500 & 575100 & 27263 & 2952849 \\
\hline 2011 & 199500 & 623438 & 149000 & 584557 & 29670 & 2306923 \\
\hline 2012 & 205000 & 615000 & 176000 & 918000 & 30266 & 2300779 \\
\hline
\end{tabular}

Fonte: IBGE, Diretoria de Pesquisas, Coordenação de Agropecuária, Produção Agrícola Municipal 2010.

Adaptado pelos autores a partir de Pereira (2014).

A expressiva produção de grãos tanto atraiu importantes cooperativas quanto a instalação das mesmas também proporcionou os canais de aquisição e comercialização, consolidando a atividade no município. Em 11 de junho de 2012, instalou-se a Coamo, que armazena soja e milho. A Copasul trabalha com soja, miIho, sorgo, girassol, algodão. Também estão instaladas as Cooperativas Lar (que adquiriu instalações da extinta Cooagri) e a Cargill, que recebe soja e milho. Lar e Coamo tem matrizes no estado do Paraná, respectivamente nos municípios de Medianeira e Campo Mourão. Lar, Coamo e Cargill estão estrategicamente instaladas às margens do ramal ferroviário da antiga Noroeste do Brasil, que está sob concessão da América Latina Logística, porém encontra-se desativado a espera da implantação de projeto de reestruturação), assim como outros projetos de infraestrutura, está parado o projeto de estender o ramal de Maracaju a Dourados e Cascavel, fazendo a ligação com o Porto de Paranaguá, ver figura 5.

A produção de grãos nessa área da bacia é significativa e seus agentes de comercialização tem contratos de venda com vários países europeus, colocando as cooperativas entre as maiores empresas exportadoras do Estado, como podemos confirmar nos trabalhos de Lamoso (2012) como também de Melo e Lamoso (2015).

$\mathrm{E}$, a terceira medida locacional, o coeficiente de redistribuição, tem como função verificar o grau de dispersão do emprego em determinado setor em relação ao transcurso do tempo. Quando o valor do índice se aproxima de zero, isto indica que o setor se tornou mais concentrado ao longo do tempo. Ou seja, a quantidade de empregos formais de determinada atividade econômica foi restringida para um menor número de municípios. Todavia, quando o valor se aproxima de um isto implica que o setor se tornou mais disperso na região ao longo do tempo. Assim, tal atividade econômica teria empregos formais distribuídos em um maior número de municípios. Onde pode-se apontar como um destes setores na bacia do Ivinhema o de criação de suínos $(0,69)$, conforme a tabela 5 , como o de mais alto valor em termos de dispersão. Por conseguinte, pode-se afirmar que o setor de criação de suínos foi aquele em que os empregos formais ampliaram-se para um maior número de municípios. O qual foi seguido pelo setor de aves $(0,57)$. 

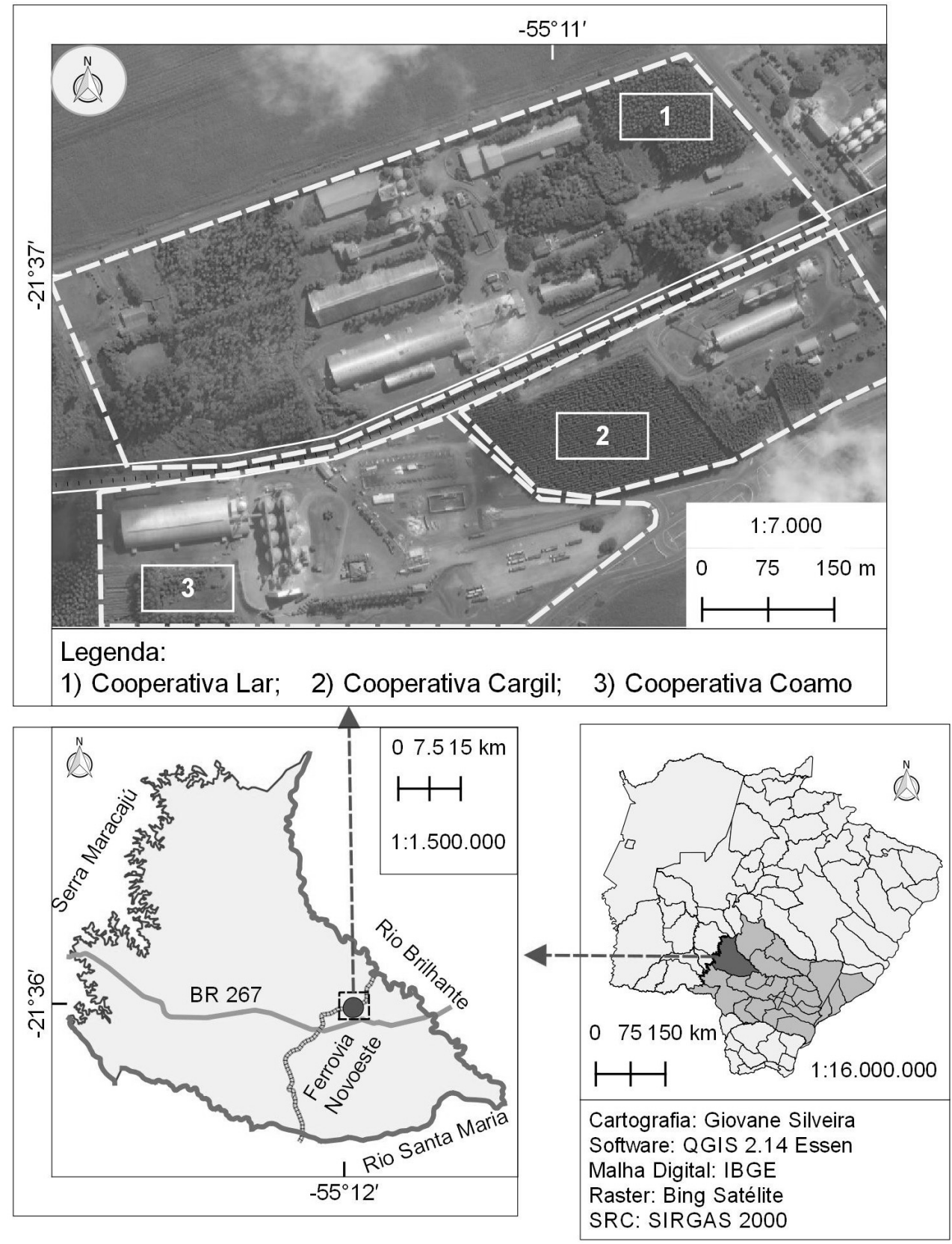

Figura 5 - Cooperativas Lar, Coamo e Cargil instaladas junto à estrada férrea Noroeste do Brasil

Fonte: Elaborada a partir de Pereira (2014). 
Tabela 5 - Coeficiente de Redistribuição para a Bacia do Ivinhema

\begin{tabular}{c|ccc|ccc|cc}
\hline \multirow{2}{*}{ Ano } & \multicolumn{3}{|c|}{ Cultivo } & \multicolumn{3}{c|}{ Criação } & \multicolumn{2}{c}{ Serviços } \\
& Cereais & Cana & Soja & Bovinos & Suínos & Aves & Agricultura & Pecuária \\
\hline $2014-1995$ & 0,21 & 0,52 & 0,55 & 0,18 & 0,69 & 0,57 & 0,51 & 0,54 \\
\hline
\end{tabular}

Fonte: elaboração própria a partir dos dados de RAIS-CAGED-MTE.

Por meio da figura 6 é possível observar uma mudança espacial na alocação da atividade de criação de suínos que em 1995 restringia-se à Alta Sub-Bacia do Ivinhema e em 2004 e 2014 desloca-se para a Baixa Sub-Bacia do Ivinhema. Destaca-se que na Baixa Sub-Bacia do Ivinhema, em especial ao sul do rio Ivinhema, o solo é conjugado pelo Podzólico Vermelho-Amarelo onde "ocorre relevo desde plano a ondulado, embora predominem suave ondulado e ondulado" (Oliveira, Urchei e Fietz, 2000, p. 20) com Latossolo Vermelho-Escuro no qual "A principal limitação ao uso agrícola destes solos refere-se à baixa fertilidade natural e a ocorrência de alumínio trocável em níveis tóxicos", (Oliveira, Urchei e Fietz, 2000, p. 17) o que pode colaborar na expansão, ou deslocamento espacial, de tal atividade de criação suína para a área em questão.
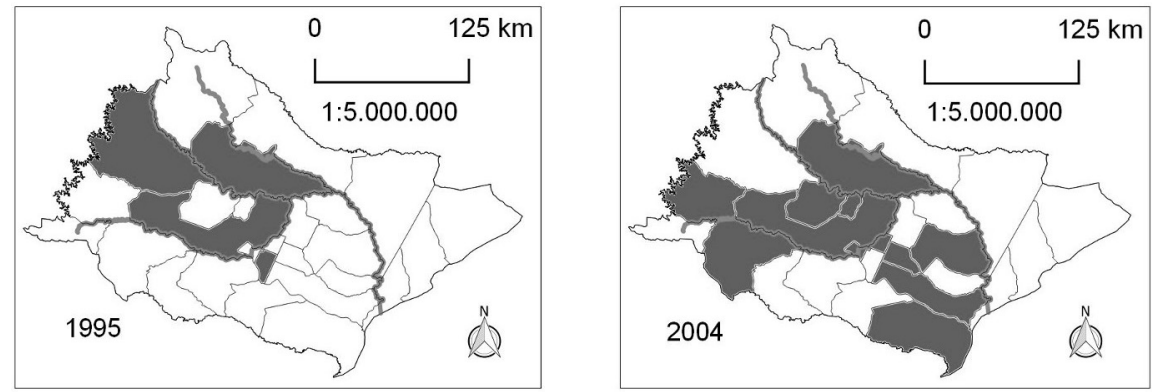

Legenda
Municípios com
criaçao de:
$\quad$ Suínos

Cartografia: Giovane Silveira da Silveira Software de Cartomática: QGI 2.14 Essen Malha Digital: IBGE e ANA

Fonte de dados: RAIS/CAGED

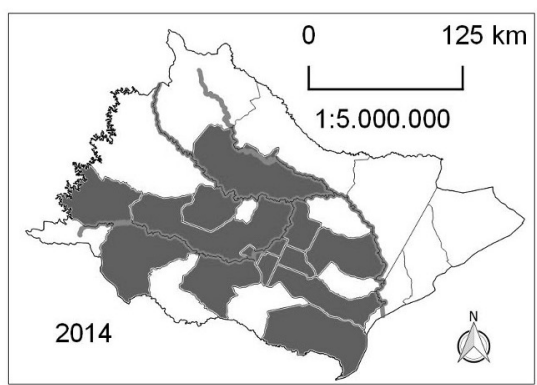

Figura 6 - Municípios da UPG Ivinhema que apresentam criação de suínos para os anos de 1995, 2004 e 2014

A produção de suínos que se expande para os municípios de Caarapó, Deodápolis, Dourados, Fátima do Sul, Glória de Dourados, Itaporã, Ivinhema, Jateí, Naviraí, Ponta Porã, Rio Brilhante, Sidrolândia e Vicentina, no ano de 2014, resulta 
também da transição do abate dos grupos de capital regional para as empresas internacionalizadas, com maior capacidade de abate e inserção internacional, como a BRFoods e JBS. (LIMA; LAMOSO, 2015). Estas empresas se organizaram a partir de projetos brownfields, instalando-se nos municípios de Dourados, Caarapó e Sidrolândia, ver tabela 6 .

\section{Tabela 6 - Fusões e aquisições de empresas do setor avícola em Mato Grosso do Sul entre os anos de 2009-2013}

\begin{tabular}{lccc}
\hline $\begin{array}{c}\text { Empresa envolvida na } \\
\text { fusão ou aquisição }\end{array}$ & $\begin{array}{c}\text { Resultantes de } \\
\text { fusão ou aquisição }\end{array}$ & Município & $\begin{array}{c}\text { Ano da } \\
\text { negociação }\end{array}$ \\
\hline Perdigão & BRF* & Dourados & 2009 \\
\hline Doux-Frangosul & JBS & Caarapó & 2012 \\
\hline Seara Alimentos & JBS & Sidrolândia & 2013 \\
\hline * A BRF foi uma empresa criada pela fusão da Perdigão e da Sadia, tornando-se \\
$\begin{array}{l}\text { uma das maiores empresas processadoras de aves do Brasil, como parte da } \\
\text { estratégia de fortalecimento dos grupos privados nacionais, com aporte do } \\
\text { BNDESPar. }\end{array}$
\end{tabular}

Fonte: adaptado pelos autores a partir de Lima e Lamoso (2015).

A internacionalização do setor avícola aumentou a capacidade de processamento e estabeleceu níveis de demanda elevados para o alojamento das aves, implantando o sistema Dark House, caracterizado pela maior automação (comedouros automáticos, bebedouros nipple, exaustores em pressão negativa, sistema de nebulização para conforto térmico, controle de iluminação e de troca de ar com o exterior, entre outros), maior capacidade de alojamento, redução no tempo médio de abate. Isto foi possível porque a região, desde os anos setenta, tem sido dotada de infraestrutura com rede de estradas vicinais, eletrificação rural e telecomunicações.

Assim, percebe-se como fatores físicos e sócio-econômicos se complementam e são mediados por políticas públicas de investimento, como subsídios fiscais, crédito, oferta de infraestrutura e mesmo de terrenos para a implantação e, assim, colaboram no processo de (re)produção do espaço das estruturas produtivas do setor primário da economia que se realiza nos municípios que compõe a Unidade de Planejamento do Ivinhema, em Mato Grosso do Sul.

\section{CONSIDERAÇÕES FINAIS}

Ao utilizar medidas locacionais para diagnosticar a forma como se espacializa as atividades agropecuárias na UPG Ivinhema temos a possibilidade de quantificar e cartografar as transformações nas estruturas produtivas, servido como rigoroso padrão de interpretação para a geografia regional. Os dados devem ser cotejados com a literatura especializadas e instigam a novas questões e agendas de pesquisa. É também, possível recuperar o conhecimento sobre as características ditas como físicas, como o relevo regional e rede hidrográfica, inter-relação sempre necessária para que possamos nos aproximar do real.

A pesquisa apontou as vantagens comparativas na produção de commodities e como a utilização dos recursos naturais tem se combinado com políticas públicas de investimento e gerado uma densificação técnica do território, com expansão das estruturas produtivas e inserção no mercado internacional. 


\section{REFERÊNCIAS}

BERTHOLI, A. O lugar da pecuária na formação sócio-espacial sulmatogrossense. 2006. Dissertação (Mestrado em Geografia). Centro de Filosofia e Ciências Humanas. Universidade Federal de Santa Catarina, 2006.

BETARELLI JUNIOR, A. A.; SIMÕES, R. F. A dinâmica setorial e os determinantes locacionais das microrregiões paulistas. Economia Aplicada. [s.I.], v. 15, n. 4, p.641670, dez. 2011. FapUNIFESP (SciELO).

DIBIESO, E. P. Planejamento Ambiental e Gestão dos Recursos Hídricos: Estudo Aplicado À Bacia Hidrográfica do Manancial do Alto Curso do Rio Santo Anastácio São Paulo/Brasil. 2013. 301f. Tese (Doutorado) Faculdade de Ciências e Tecnologia, Universidade Estadual Paulista, Presidente Prudente, 2013.

BRASIL. Departamento de Cartografia . Instituto de Geografia e Estatística. Noções

Básicas de Cartografia. Rio de Janeiro: Ministério do Planejamento e Orçamento, 1998. $128 \mathrm{p}$.

FRATA, A. M.; DEFARIA, A. B. A expansão da cana-de-açúcar e o recorte em bacias hidrográficas: o etanol na sub-bacia do rio Ivinhema. In: CONGRESSO DA SOCIEDADE BRASILEIRA DE ECONOMIA E SOCIOLOGIA RURAL, 48., 2010, Campo Grande. Anais... Campo Grande: Sober, 2010. p. 1 - 21.

GALERA, M. M. A inserção dos frigoríficos exportadores de Mato Grosso do Sul no mercado global. Dissertação (Mestrado em Geografia). Universidade Federal da Grande Dourados, 2011. Disponível em http://tede.ufgd.edu.br/jspui/handle/tede/ 377.

IMASUL. Governo do Estado de Mato Grosso do Sul. Plano Estadual de Recursos Hídricos: PERH/MS. Campo Grande: UEMS, 2010. 196 p.

LAMOSO, L. P. Dinâmicas Produtivas da Economia de Exportação no Mato Grosso do Sul-Brasil. Mercator, [s.I.], v. 10, n. 21, p.33-47, 30 abr. 2011. Mercator - Revista de Geografia da UFC. http://dx.doi.org/10.4215/rm2011.1021.0002.

LIMA, A. C. da C.; SIMOES, R. F. Centralidade e emprego na região Nordeste do Brasil no período 1995/2007. Nova econ., Belo Horizonte, v. 20, n. 1, p. 39-83, Apr. 2010 http://dx.doi.org/10.1590/S0103-63512010000100002.

LIMA, F. de; LAMOSO, L. P. Origem da indústria de frangos em Dourados/MS e o sistema de parceria entre a empresa BR Foods com os avicultores integrados. Anais ... SINGA, 2015, Goiânia-GO. Simpósio Internacional de Geografia Agrária - SINGA., 2015. p. 3443-3452.

LOUVEIRA, L. R.; LAMOSO, L. P. Produção do Espaço na Bacia do Médio Ivinhema-MS. Geografia, Rio Claro, v. 31, n. 1, p.83-100, abr. 2006.

MELO, T. da S.; LAMOSO, L. P. Territorialidade econômica e estratégias globais do setor agroindustrial no Mato Grosso do Sul. Revista Espacios, v. 36, n.23, 2015.

MTE. Características do Emprego Formal segundo a Relação Anual de Informações Sociais: RAIS 2013. Brasília: Secretaria de Políticas Públicas de Emprego, 2013. 23 p. Coordenação Geral de Estatísticas do Trabalho.

MTE. Nota Técnica MTE 093/2014 (13/08/2014): Base de Dados RAIS/2013. Brasilia: Secretaria de Políticas Públicas de Emprego, 2014. 5 p. Coordenação Geral de Estatísticas do Trabalho. 
OLIVEIRA, R. C. de. Zoneamento ambiental como subsídio para o planejamento de uso e ocupação do solo do município de Corumbataí - SP. 2013. 149 f. Tese (Doutorado) - Curso de Pós Graduação em Geociências - Área de Concentração em Geociências e Meio Ambiente, Campus de Rio Claro, Universidade Estadual Paulista, Rio Claro, 2013.

OLIVEIRA, H. de; URCHEI, M. A.; FIETZ, C. R. Aspectos físicos e socioeconômicos da Bacia Hidrográfica do Rio Ivinhema. Dourados: Embrapa Agropecuária Oeste, 2000.

PEREIRA, T. B. Características da agropecuária no município de MaracajuMS. Monografia (Bacharelado em Geografia). Dourados, Universidade Federal da Grande Dourados, 2014.

ZANATTA, F. A. S. Diagnóstico Visando Planejamento Ambiental da Alta Bacia do Ribeirão Areia Dourada: Marabá Paulista (SP). 2014. 154 f. Dissertação (Mestrado) - Curso de Programa de Pós-graduação em Geografia - Organização do Espaço, Instituto de Geociências e Ciências Exatas - IGCE, Universidade Estadual Paulista, Rio Claro, 2014.

Recebido em novembro de 2016 Aceito em março de 2017 
